\title{
INFLAMMATORY MARKERS IN PRE-DIABETICS
}

\author{
Soma Bose1, Chittaranjan Maity2, Nirmala Roy ${ }^{3}$
}

1 Post Graduate Trainee, Department of Biochemistry, KPC Medical College \& Hospital, Jadavpur, Kolkata.

2 Professor \& HOD, Department of Biochemistry, KPC Medical College \& Hospital, Jadavpur, Kolkata.

${ }^{3}$ Associate Professor, Department of Medicine, KPC Medical College \& Hospital, Jadavpur, Kolkata.

\section{ABSTRACT}

\section{BACKGROUND}

Pre-diabetes is the clinical stage in which blood glucose level of a person is higher than normal, but not yet high enough to be classed as diabetes. Without lifestyle changes to improve their health, most of the people with pre-diabetes will develop Type-2 diabetes within five years.

\begin{abstract}
AIMS AND OBJECTIVES
Progression of type-2 diabetes from pre-diabetic condition may involve various inflammatory mechanisms, which induce insulin resistance and beta cells dysfunction. Obesity, particularly visceral obesity results in a pro-inflammatory state starting in the metabolic cells (Adipocytes, hepatocytes and myocytes) and also recruiting immune cells with the consequent release of proinflammatory cytokines - Tumour necrosis factor $\alpha / \mathrm{TNF} \alpha$, Interleukin-6/IL-6, etc. To combat internal harm of inflammations, liver cells produce high sensitivity C-reactive protein/hs-CRP. We have conducted this study to estimate inflammatory markers in prediabetics to identify the individuals who are at high risk, to prevent development of Type 2 diabetes and other complications related to the disease.
\end{abstract}

\section{MATERIALS AND METHODS}

In our present study we included 60 pre-diabetic subjects, selected from Medicine OPD of KPC Medical College on the basis of Impaired Fasting Glucose 100-125 mg/dL, Impaired Glucose Tolerance or two-hour glucose levels on 75-g oral glucose tolerance test) $140-199 \mathrm{mg} / \mathrm{dL}$, waist circumference: male $>90 \mathrm{~cm}$, female $>80 \mathrm{~cm}, \mathrm{BMI} \geq 25$, BP $>130 / 85 \mathrm{mmHg}$, Triglycerides $>200$ or HDL $<35$ and HBA1C (5.7\%-6.4\%); 60 normo-glycaemic subjects are also taken as controls. Overnight fasting venous blood samples are collected from cases and controls to estimate fasting blood glucose, fasting insulin, TNF- $\alpha$, IL- 6 and hs-CRP. We have calculated HOMA-IR and correlated it with the findings.

\section{RESULTS}

We have found that HOMA-IR of pre-diabetic study group is significantly correlated with TNF- $\alpha$ ( $\mathrm{r}=0.925)$ and IL-6 (r=0.766) respectively. There is also significant positive correlation in between the TNF- $\alpha$ and hs-CRP of pre-diabetics in this study ( $\mathrm{r}=0.831$ ).

\section{CONCLUSIONS}

These results suggest that TNF- $\alpha$, IL- 6 as well as hs-CRP increase in pre-diabetic condition and systemic inflammations play an important role in the progression of pre-diabetes to diabetes and other complications.

\section{KEYWORDS}

Pre-Diabetes, Pro-inflammatory Cytokines, TNF- $\alpha$, IL-6, hs-CRP, HOMA-IR, Insulin Resistance, Type-2 Diabetes.

HOW TO CITE THIS ARTICLE: Bose S, Maity C, Roy N. Inflammatory markers in pre-diabetics. J. Evolution Med. Dent. Sci. 2016;5(35):2056-2060, DOI: 10.14260/jemds/2016/482

\section{INTRODUCTION}

Pre-diabetic individuals are diagnosed by the Impaired Fasting Glycaemia (IFG), having higher than normal glucose level after a period of fasting and Impaired Glucose Tolerance (IGT), having higher than normal post-prandial glucose level and also glycated haemoglobin (HbA1C) in the range 5.76.4.[1] According to the criteria of World Health Organisation (WHO), Impaired Fasting Glucose is defined as: Fasting plasma glucose level of $6.1 \mathrm{mmoL} / \mathrm{l}-6.9 \mathrm{mmol} / \mathrm{L}(110-125$ $\mathrm{mg} / \mathrm{dL}) \cdot{ }^{[2]}$

Financial or Other, Competing Interest: None.

Submission 15-03-2016, Peer Review 14-04-2016,

Acceptance 18-04-2016, Published 02-05-2016.

Corresponding Author:

Dr. Soma Bose (Lahiri),

Flat No. A-7/8, E.K.T.P. (Phase-1),

E. M. Bypass,

Kolkata, West Bengal.

E-mail: drslahiri@yahoo.co.in

DOI: $10.14260 /$ jemds $/ 2016 / 482$
The American Diabetes Association (ADA) since 2003 uses a slightly different range for Impaired Fasting Glucose of $5.6 \mathrm{mmol} / \mathrm{L}-6.9 \mathrm{mmol} / \mathrm{L}(100-125 \mathrm{mg} / \mathrm{dL})$. According to World Health Organization and the American Diabetes Association, both Impaired Glucose Tolerance is defined as two-hour glucose levels of 7.8 - $11.0 \mathrm{mmol} / \mathrm{L} \mathrm{(140-199} \mathrm{mg}$ per $\mathrm{dL}$ ) on 75 -g oral glucose tolerance test.[3,4] Pre-diabetic individuals are at higher risk for developing type 2 diabetes and also different complications related to this disease. High risk group among pre-diabetics who have age $>45$ years, family history of diabetes (Parent or sibling), history of gestational diabetes, infant born with birth weight $>9$ lb (4 $\mathrm{kg}$ ), high risk ethnic group, known vascular disease, markers of insulin resistance (PCOS, Acanthosis Nigricans), etc. [5,6]

Other risk factors of pre-diabetic persons for development Type 2 diabetes and its related complications are: triglycerides $>200 \mathrm{mg} / \mathrm{dL}$ or $\mathrm{HDL}<35 \mathrm{mg} / \mathrm{dL}$, overweight or obesity (Body Mass Index or BMI $>25$ ), hypertension (BP >135/85 mmHg), low-grade inflammation with elevated pro-inflammatory cytokines like Interleukins (IL-1, IL-6, etc.) ${ }^{[7,8]}$ and Tumour Necrosis Factor Alfa (TNF $\alpha$ ), 
elevated high sensitivity C-Reactive protein (hs-CRP), prothrombotic state with increased PAI-1 and Fibrinogen, increased uric acid levels (Caused by dietary fructose) and others. ${ }^{[9]}$

The link between obesity and inflammation has been derived from the finding that pro-inflammatory cytokines are over expressed in obesity.[10] Adipose tissue is a heterogeneous mix of adipocytes, stromal pre-adipocytes, immune cells and endothelium and it can respond rapidly and dynamically to alterations in nutrient excess through adipocyte hypertrophy and hyperplasia.[10,11,12] With obesity and progressive adipocyte enlargement, the blood supply to adipocytes may be reduced with consequent hypoxia. Hypoxia has been proposed to be an inciting aetiology of necrosis and macrophage infiltration into adipose tissue that leads to an overproduction of pro-inflammatory factors.[12]

In obese men and women if compared with lean controls, adipose tissue and liver display an increased activation of three kinases able to induce the expression of inflammatory cytokines.[13] The C-Jun N-terminal Kinase (JNK), the Inhibitor of K Kinase (IKK) and the Protein Kinase C (PKC).[13,14] In the same metabolic tissues, the inflammasome and the Toll-Like Receptors (TLRs) of the innate immune system are also activated.[14] Nutrients or inflammatory signals may activate the TLRs pathways and downstream JNK, IKK and PKC.[14,15] These kinases regulate downstream transcriptional programs through the transcription factors activator protein-1 (AP-1), NF- $\kappa B$ and Interferon Regulatory Factor (IRF), inducing up regulation of inflammatory mediator gene expression. The increase in cytokines exacerbates receptor activation by establishing a positive feedback loop of inflammation and the inhibitory signalling of metabolic pathways.[15]

To combat internal harm of inflammations, liver cells produce high sensitivity C-reactive protein/hs-CRP in response to TNF- $\alpha$ and IL- 6 produced by adipocytes as well as macrophages (Vide Figure 1).

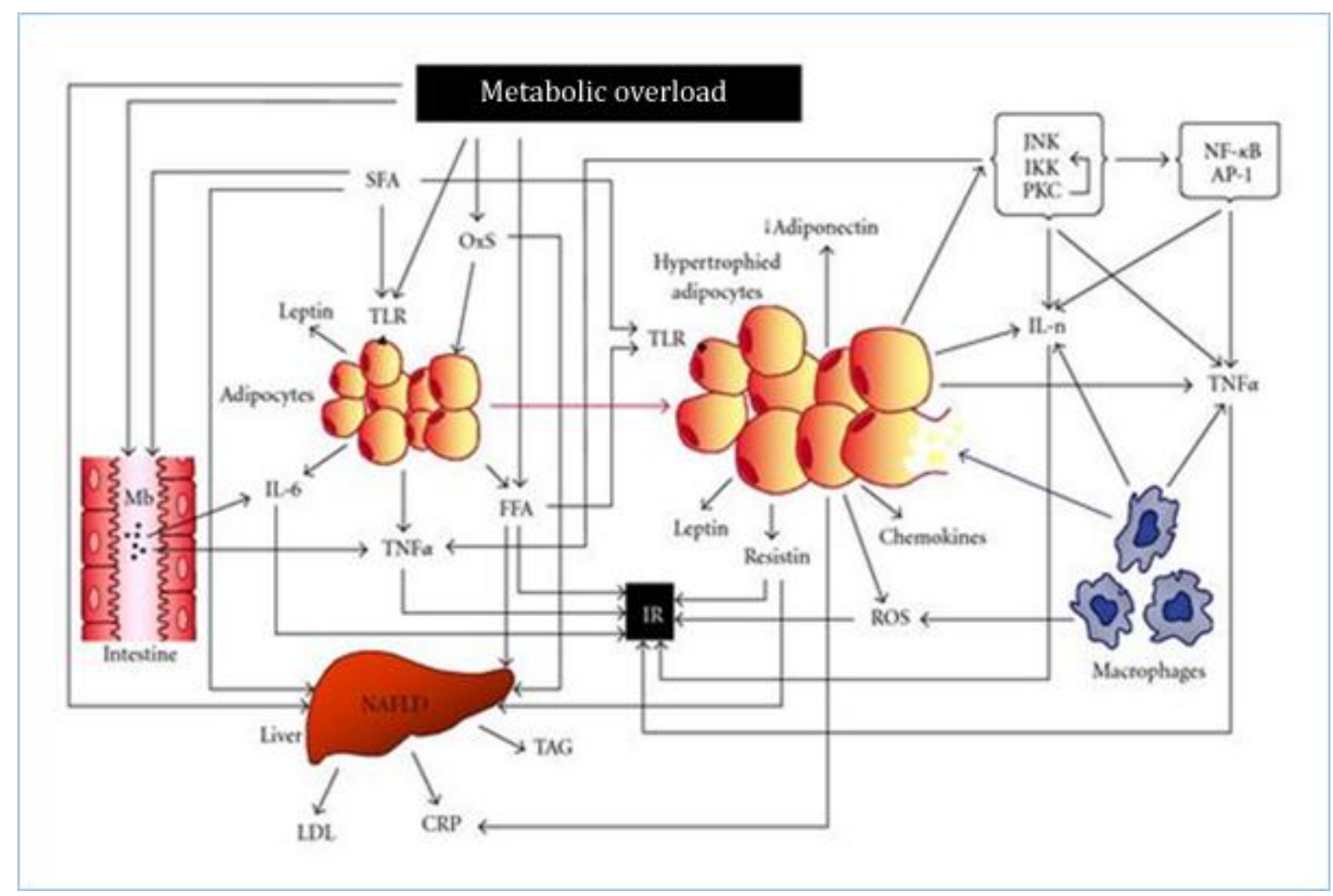

Fig. 1

\section{JNK- C-Jun N-terminal kinase, IKK- Inhibitor of K kinase, PKC-Protein Kinase C, TLR-Toll-like receptors, AP1-Transcription factors activator protein-1, NF- $\boldsymbol{B} B$ - Nuclear Factor K beta, FFA-Free fatty acid, TAG-Triacylglycerol, LDL-Low density lipoprotein, IR-Insulin resistance, ROS-Reactive oxidase stress, NAFLD-Non-alcoholic fatty liver disease}

\section{AIMS AND OBJECTIVES}

In last few years, numerous studies have shown low-grade inflammation in pre-diabetic state is associated with high risk of developing type-2 diabetes. Furthermore, now-a-days it is accepted that chronic subclinical inflammation is a part of the insulin resistance syndrome.[15] The pancreatic beta cells can no longer produce enough insulin to overcome insulin

resistance, causing blood glucose rise above the normal range, i.e. prolonged low-grade inflammation during pre- diabetic state facilitate onset of diabetes and its related complications.[16] Epidemiological evidence also supports the facts that pro-inflammatory markers predict the development of diabetes and glucose disorder.[17,18] However, there are also some studies which do not support this.

So we did a prospective, cross-sectional, descriptive and observational hospital-based study in a reference population of pre-diabetic individuals irrespective of age and sex to identify those individuals at high risk early, so that their 
lifestyle interventions and treatment may prevent the development of Type 2 Diabetes and/or Cardiovascular disease as well as the long-term complications affecting the eyes, kidneys and nervous system and also to prevent cerebrovascular accident.

\section{MATERIALS AND METHODS}

The study was carried out at the outpatient clinic of Department of Medicine in KPC Medical College and Hospital, Jadavpur, Kolkata, for a period of one year from inception. Patients were chosen from outdoor of Medicine Department of KPC Hospital. Our study group comprise of 60 prediabetics patients, age within 35-65 years having IFG, IGT and HbA1C 5.7-6.4 with/without family history of diabetes; 60 normo-glycaemic healthy persons who were in the same age group as our study group also taken as control. All biochemical tests were carried out at the Department of Biochemistry in KPC Medical College and Hospital, Kolkata.

Patients with history of Acute myocardial infarction, Heavy injuries, Acute or Chronic renal failure, Hyperglycaemic crisis (FBG $\geq 250 \mathrm{mg} / \mathrm{dL}$ or $\mathrm{PPBG} \geq 300$ $\mathrm{mg} / \mathrm{dL}$ or $\mathrm{HbA1c}>10 \%$ ), severe hypertriglyceridemia (TG $>400 \mathrm{mg} / \mathrm{dL}$ ) were excluded from the study. Patients were selected after taking their interviews and history and also by clinical examination. Important clinical examinations which were included in our study were - patient's Height, Weight, Skin Tag, Signs of Pallor, Oedema, Jaundice, Cyanosis, clubbing, palpable Neck glands and engorged Neck veins, presence of Acanthosis nigricans, etc. We also measured Waist circumferences, Hip circumferences and Neck circumferences of the patients.

Their essential parameters like pulse, BP, Temperature were recorded. Overnight (12 hours) fasting venous blood samples are collected from cases and controls for the estimation of fasting blood glucose, fasting insulin, TNF- $\alpha$, IL6 and hs-CRP. (Fasting insulin, TNF- $\alpha$, IL- 6 were estimated by their respective ELISA kit and hs-CRP is estimated by latexagglutination test in Microbiology Department of KPC Medical College).

\section{RESULTS AND ANALYSIS}

A total of 60 pre-diabetic persons were included in this study, which comprised of 24 males and 36 females in a range of 3565 years; 60 healthy individuals of same age were also taken as controls, of them 32 were male and 28 were female. All the biochemical parameters like fasting blood glucose, fasting insulin, TNF- $\alpha$, IL- 6 , hs-CRP were elevated at significant level in pre-diabetic study group than that of healthy controls. (Vide Table 1 and 2, Figure 2 and 3). We have calculated HOMA-IR.[19] with the formulae, HOMA-IR=[Glucose $x$ Insulin]/22.5 (Glucose in Molar Units mmol/L).[20] or HOMAIR=[Glucose $x$ Insulin]/405 (Glucose in mass units $\mathrm{mg} / \mathrm{dL}$ ). [21] and correlated it statistically with other findings by Student's T-test.

\begin{tabular}{|c|c|c|c|}
\hline DESCRIPTION & $\begin{array}{c}\text { FASTING } \\
\text { BLOOD } \\
\text { GLUCOSE } \\
(\mathbf{m g} / \mathbf{d L})\end{array}$ & $\begin{array}{c}\text { FASTING } \\
\text { INSULIN } \\
(\boldsymbol{\mu} \text { IU } / \mathbf{L})\end{array}$ & HOMA-IR \\
\hline CASES $(\mathrm{n}=60)$ & $117.38 \pm 3.21$ & $7.96 \pm 1.06$ & $2.33 \pm 0.36$ \\
\hline $\begin{array}{c}\text { CONTROLS } \\
(\mathrm{n}=60)\end{array}$ & $83.32 \pm 2.78$ & $5.51 \pm 0.36$ & $1.19 \pm 0.16$ \\
\hline “t” VALUE & 13.85 & 8.07 & 6.12 \\
\hline
\end{tabular}

\begin{tabular}{|c|c|c|c|}
\hline $\begin{array}{c}\text { LEVEL OF } \\
\text { SIGNIFICANCE } \\
\text { (p) VALUE }\end{array}$ & $<0.00001$ & $<0.00001$ & $<0.00001$ \\
\hline \multicolumn{3}{|c|}{ Table 1: Levels of Fasting Blood Sugar, Fasting Insulin \& } \\
Homa-IR of Pre-Diabetic Individuals (Cases) Compared \\
to that of Control Group \\
\hline
\end{tabular}

\begin{tabular}{|c|c|c|c|}
\hline DESCRIPTION & $\begin{array}{c}\text { TNF- } \alpha \\
(\mathrm{pg} / \mathrm{mL})\end{array}$ & $\begin{array}{c}\text { IL-6 } \\
(\mathrm{pg} / \mathrm{mL})\end{array}$ & hs-CRP \\
\hline CASES $(n=60)$ & $5.86 \pm 1.23$ & $2.61 \pm 0.78$ & $11.99 \pm 3.51$ \\
\hline $\begin{array}{c}\text { CONTROLS } \\
(\mathrm{n}=60)\end{array}$ & $3.65 \pm 0.30$ & $0.97 \pm 0.09$ & $5.11 \pm 1.46$ \\
\hline "t" VALUE & 7.41 & 6.87 & 2.29 \\
\hline (p) VALUE & $<0.00001$ & $<0.00001$ & $<0.00001$ \\
\hline \multicolumn{4}{|c|}{$\begin{array}{l}\text { Table 2: Levels of TNF- } \alpha, \text { IL-6 \& hs-CRP of Pre-Diabetic } \\
\text { Individuals (Cases) Compared to that of Control Group }\end{array}$} \\
\hline
\end{tabular}

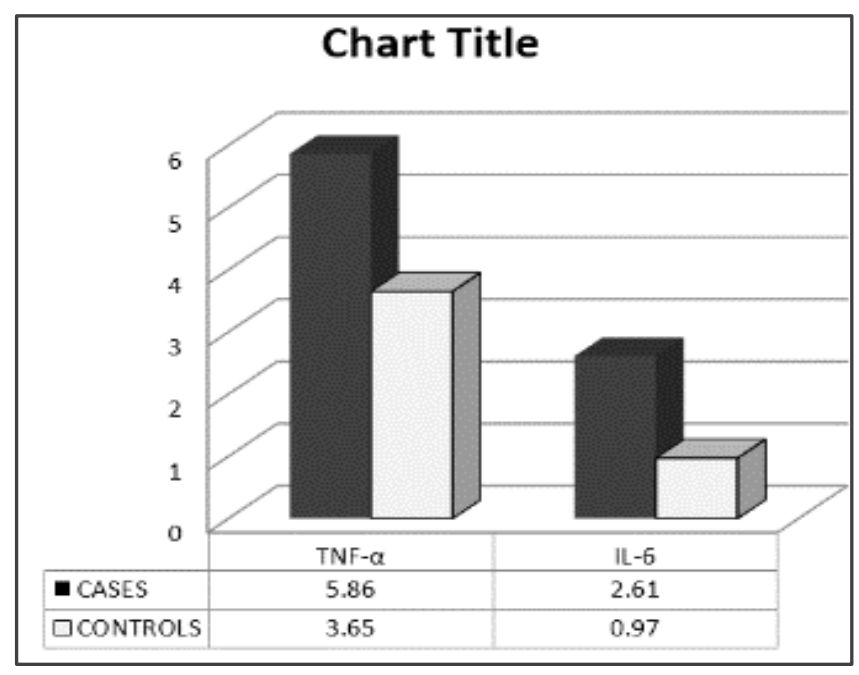

Fig. 2: Bar Diagram shows TNF- $\alpha$ \& IL-6 in Pre-Diabetic Study Group \& Healthy Control Group

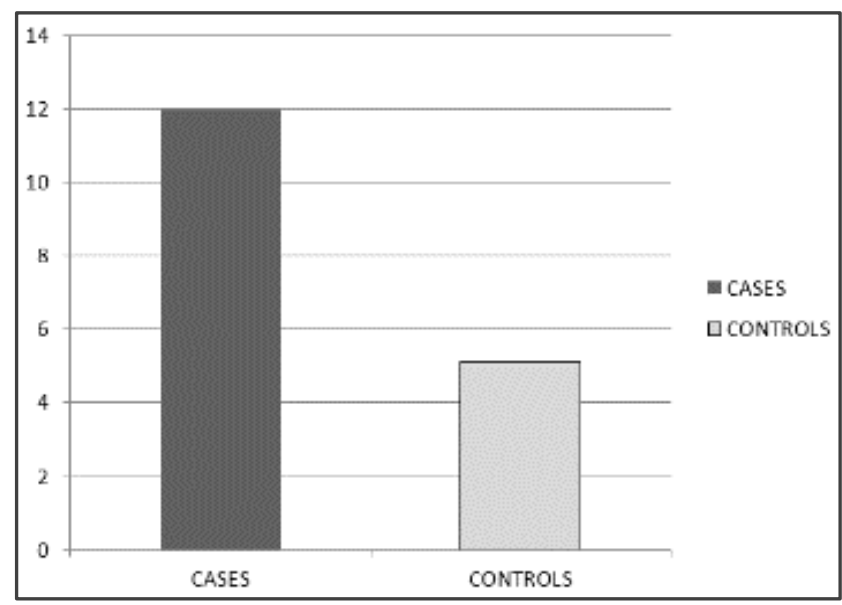

Fig. 3: Bar Diagram shows hs-CRP in Pre-Diabetic Study Group \& Healthy Control Group

In this study, it is found that HOMA-IR is significantly (Positively) correlated with two pro-inflammatory parameters TNF- $\alpha$ and IL- 6 in pre-diabetic study group. Correlation coefficient in between HOMA-IR and TNF- $\alpha$ is, $r=$ 0.925 , which is very highly significant at $p<0.00001$ (Vide Figure 4).

IL-6 of pre-diabetics is also significantly and positively correlated with their HOMA-IR.

Correlation coefficient $r=0.766$ at $p<0.00001$ (Vide Figure $5)$. 


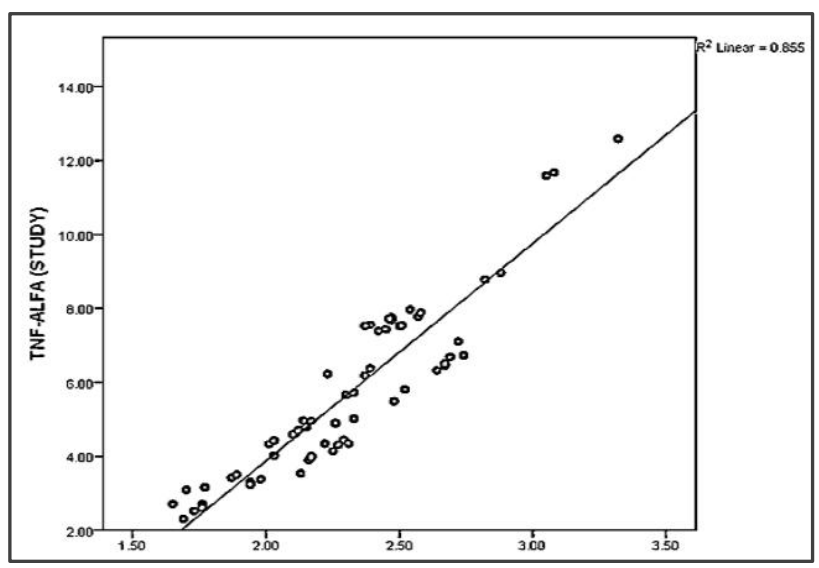

Fig. 4: Scattered Diagram shows Correlation in between Homa-IR \& TNF- $\alpha$ of Pre-Diabetic Study Group $(r=0.925)$

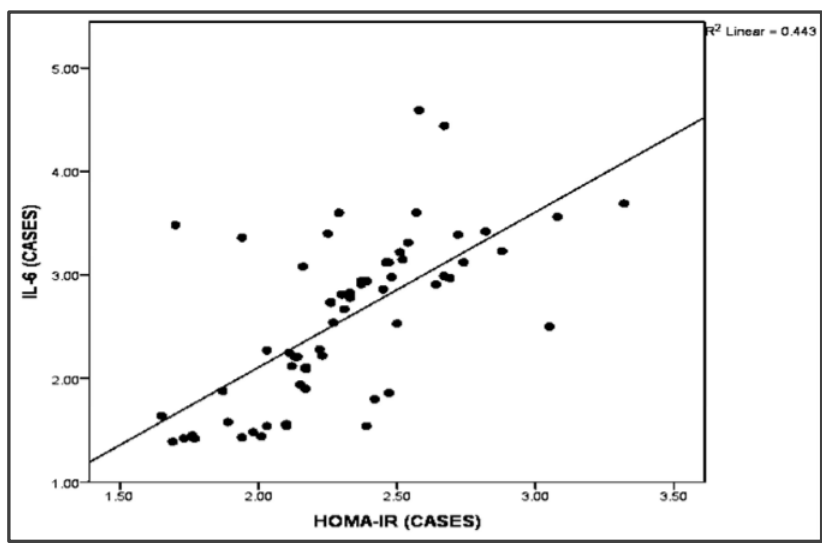

Fig. 5: Scattered Diagram shows Correlation in between HOMA-IR \& IL-6 of Pre-Diabetic Study Group ( $r=0.766)$

In our study, pro-inflammatory marker TNF- $\alpha$ of prediabetic study group is also significantly and positively correlated with their hs-CRP, correlation cofficient $r=0.831$, which is also very highly significant at $p<0.00001$ (Vide Figure 6).

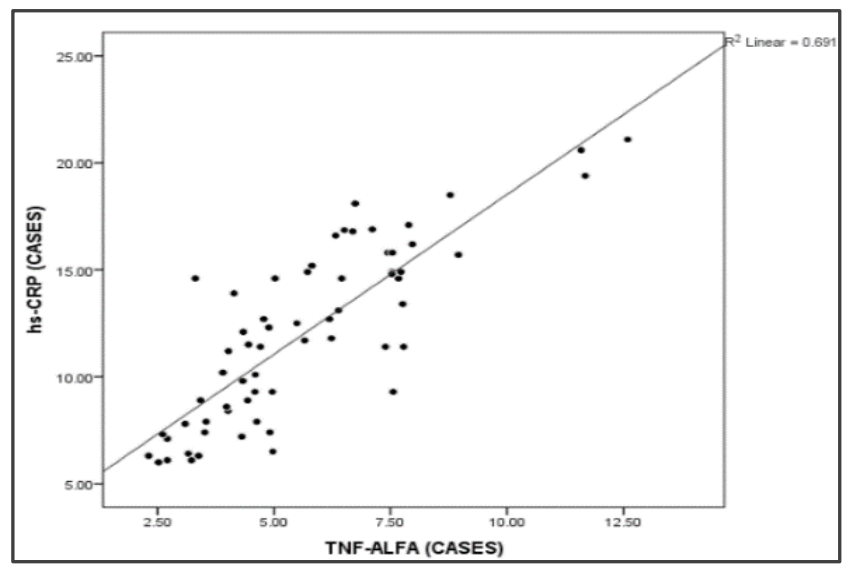

Fig. 6: Scattered Diagram shows Correlation in between TNF- $\alpha$ \& hs-CRP of Pre-Diabetic Study Group ( $r=0.831)$

\section{DISCUSSION}

In this cross-sectional study different inflammatory parameters of sixty middle aged, obese/overweight women and men with central obesity, dyslipidaemia and pre-diabetes with IFG and IGT were evaluated and the results were analysed statistically. In Table 1 and 2 we can see that mean fasting blood glucose, fasting insulin, TNF- $\alpha$, IL- 6 and hs-CRP are significantly increased in pre-diabetic study group than the healthy controls. We have calculated HOMA-IR from their fasting blood glucose, fasting insulin which was correlated with both TNF- $\alpha$ (Correlation coefficient $r=0.925$ ) and IL-6 (Correlation coefficient $r=0.766$ ) significantly and positively in pre-diabetic individuals.

TNF- $\alpha$ is also significantly and positively correlated with hs-CRP (correlation coefficient $\mathrm{r}=0.831$ ) in pre-diabetics. So the results from this study confirmed that inflammatory markers (TNF- $\alpha$, IL-6) are increased in pre-diabetic condition and to combat internal harm, inflammation produces highly sensitivity C-reactive protein (hs-CRP).

\section{CONCLUSION}

It is already known that inflammation is part of the body's immune system, which triggers a defence response to harmful stimuli.[22] The body reacts to injury by sending specialized blood cells to damaged areas where they attack "Invaders" and clean up dead and dying cells.[22,23] In the case of inflammation and Pre-Diabetes, the "Invader" is thought to be excess levels of insulin, which can be caused by the imbalance of blood glucose and insulin called Insulin Resistance.[23] Obese subjects subsist in a heightened lowgrade systemic inflammatory milieu as overweight and they exhibit central adiposity (Increased waist circumference), the low-grade systemic inflammation is possibly resulted by an expanded visceral adipose tissue compartment.[23,24] An increased mass of dysfunctional adipose tissue in ectopic locations influences the overall total body metabolism with secretions that have auto, para and endocrine effects. Macrophage infiltration in the visceral adipose tissue generates hepatic insulin resistance and the association of chronic inflammation. $[24,25]$

Numerous studies have supported the fact that prolonged low-grade inflammation with raised inflammatory markers during pre-diabetic state facilitate onset of Type-2 Diabetes, beta-cell dysfunction and Insulin Resistance.[25,26] The changeover from the early metabolic abnormalities that antedate diabetes, Impaired Fasting Glucose (IFG) and Impaired Glucose Tolerance (IGT) to diabetes may take many years, but current estimates indicate that most individuals with these pre-diabetic states eventually end up with diabetes. Individuals who are older, overweight, having sedentary life-style and have other risk factors of diabetes are more likely to progress. ${ }^{[26,27]}$

Thus to conclude we can say that our present study may help to identify high-risked pre-diabetic individuals, so that their life-style intervention, change of diet, weight loss and proper treatment may prevent development of Type-2 diabetes and other complications related to this disease.

\section{REFERENCES}

1. Diabetes blue circle symbol. International diabetes $\begin{array}{llll}\text { federation. } & 17 & \text { March } & \end{array}$ http://www.diabetesbluecircle.org.Abdul-Ghani MA, Lyssenko V, Tuomi T, et al. Fasting versus postload plasma glucose concentration and the risk for future type 2 diabetes, results from the botnia study. Diabetes Care 2009;32(2):281-6.

2. Aroda VR, Ratner R. Approach to the patient with prediabetes. J Clin Endocrinol Metab 2008;93(9):3259-65. 
3. Diabetes Fact sheet N0 312. WHO. October 2013. Retrieved 25 March 2014.

4. Moreno-Aliaga MJ, Campion J, Milagro FI, et al. Adiposity and proinflammatory state: the chicken or the egg. J Adipocytes 2005;1:1-16.

5. Fantuzzi G. Adipose tissue, adipokines, and inflammation. J Allergy Clin Immunol 2005;115(5):911-9.

6. Vettor R, Milan G, Rossato M, et al. Review article: adipocytokines and insulin resistance. Aliment Pharmacol Ther 2005;22(2):3-10.

7. Xu H, Barnes GT, Yang Q, et al. Chronic inflammation in fat plays a crucial role in the development of obesity-related insulin resistance. J Clin Invest 2003;112(12):1821-30.

8. Hermans MP, Levy JC, Morris RJ, et al. Comparison of tests of beta-cell function across a range of glucose tolerance from normal to diabetes. Jour Diabetes 1999;48(9):177986.

9. Bourlier V, Bouloumie A. Role of macrophage tissue infiltration in obesity and insulin resistance. Diabetes Metab 2009;35(4):251-60.

10. Hotamisligil GS. Inflammation and metabolic disorders. Journal Nature 2006;444(7121):860-7.

11. Chiu HK, Tsai EC, Juneja R, et al. Equivalent insulin resistance. Diabetes Research and Clinical Practice Pub Med 2000;77:237-44.

12. Fukushima $M$, Usami $M$. Insulin secretion and insulin sensitivity at different stages of glucose tolerance: a crosssectional study of Japanese type 2 diabetes. Metabolism 2004;53(7):831-5.

13. Rudenski AS, Matthews DR. Understanding insulin resistance: both glucose resistance and insulin resistance are required to model human diabetes. Metabolism 1991;40(9):908-17.

14. Rajala MW, Scherer PE. The adipocyte at the crossroads of energy homeostasis, inflammation, and atherosclerosis. Endocrinology 2003;144(9):3765-73.

15. Olefsky J, Crapo PA, Ginsberg H, et al. Metabolic effects of increased caloric intake in man. Metabolism 1975;24(4):495-503.
16. Esposito K, Nappo F, Marfella R, et al. Inflammatory cytokine concentrations are acutely increased by hyperglycemia in humans: role of oxidative stress. Circulation 2002;106(16):2067-72.

17. Meshkani R, Adeli K. Hepatic insulin resistance, metabolic syndrome and cardiovascular disease. Clin Biochem 2009;42(13-14):1331-46.

18. Wallace TM, Levy JC, Matthews DR. Use and abuse of HOMA modeling. Diabetes Care 2004;27(6):1487-95.

19. Turner, Belfiore F, Bergman R, et al. Measurement of insulin resistance and $\beta$-cell function: the HOMA and CIGMA approach. Current topics in diabetes research (eds) front diabetes. Basel, Karger 1993;12:66-75.

20. Matthews DR, Hosker JP, Rudenski AS, et al. Homeostasis model assessment: insulin resistance and beta-cell function from fasting plasma glucose and insulin concentrations in man. Diabetologia 1985;28(7):412-9.

21. Hotamisligil GS, Shargill NS, Spiegelman BM. Adipose expression of tumor necrosis factor- $\alpha$ : direct role in obesity-linked insulin resistance. Journal Science 1993;259(5091):87-91.

22. Hotamisligil GS, Arner P, Caro JF, et al. Increased adipose tissue expression of tumor necrosis factor- $\alpha$ in human obesity and insulin resistance. J Clin Invest 1995;95(5):2409-15.

23. Bastard JP, Jardel C, Delattre J, et al. Evidence for a link between adipose tissue interleukin- 6 content and serum C-reactive protein concentrations in obese subjects. Circulation 1999;99(16):2221-2.

24. Shanmugam N, Reddy MA, Guha M, et al. High glucoseinduced expression of proinflammatory cytokine and chemokine genes in monocytic cells. Diabetes 2003;52(5):1256-64.

25. Pradhan AD, Manson JE, Rifai N, et al. C-reactive protein, interleukin 6 , and risk of developing type 2 diabetes mellitus. JAMA 2001;286(3):327-34.

26. Natali A, Ferrannini E. Hypertension, insulin resistance, and the metabolic syndrome. Endocrinol Metab Clin North Am 2004;33(2):417-29. 